Article

\title{
Determining Shrinkage Cracks Based on the Small-Strain Shear Modulus-Suction Relationship
}

\author{
Avishek Shrestha ${ }^{1}$, Apiniti Jotisankasa ${ }^{1, * \mathbb{C}}$, Susit Chaiprakaikeow ${ }^{1}$, Sony Pramusandi ${ }^{1}$, \\ Suttisak Soralump ${ }^{1}$ and Satoshi Nishimura ${ }^{2}$ \\ 1 Geotechnical Engineering Division, Department of Civil Engineering, Kasetsart University, \\ Bangkok 10900, Thailand \\ 2 Division of Field Engineering for the Environment, Hokkaido University, Sapporo 060-8628, Japan \\ * Correspondence: fengatj@ku.ac.th
}

Received: 25 June 2019; Accepted: 20 August 2019; Published: 22 August 2019

\begin{abstract}
This research aims to propose the use of spectral analysis of surface wave (SASW) tests along with in-situ suction measurements for non-destructive determination of shrinkage cracks. The underlying principle behind this proposed method is that, while suction and the small-strain shear modulus are positively correlated for intact samples, this is not the case for cracked ground. A series of SASW tests were performed on a clay embankment at different periods, during which the suction, modulus, and shrinkage crack depth varied seasonally. The soil water retention curve (SWRC) of the undisturbed sample collected from the cracked zone was determined, which related the suction-to-moisture content and void ratio of the soil. A free-free resonant frequency (FFR) test in the lab was conducted to determine the small-strain shear modulus $\left(\mathrm{G}_{0}\right)$ at various moisture contents. The small-strain moduli from the SASW tests on the intact ground were generally higher than those from the FFR tests due to the effect of confining stress. A drop in the small-strain modulus determined using the SASW test was observed as an increase in suction-induced cracks and it relieved the horizontal stress. The crack depth measured in the field was then modelled using a semi-empirical procedure that can be used to predict crack depth relative to suction.
\end{abstract}

Keywords: shrinkage crack; unsaturated soil; soil water retention curve (SWRC); spectral analysis of surface wave (SASW); free-free resonant frequency (FFR); small-strain shear modulus

\section{Introduction}

Clay embankments or dykes are important engineering structures often used as a protective measure against floods. In a world that is oriented towards rapid urbanization, the easy availability of clay soil and its cost-effectiveness have increased the use of such structures, which is likely to grow in the future. However, the effects of ongoing climate change, such as excessive precipitation and an extended drier period, have subjected these structures to more intense wetting and drying periods. Such exposure often leads the clay soil to crack.

It has long been known that such cracks can have adverse effects on the stability of slopes [1-3]. As a result of cracks, the length of the mobilized slip surface is reduced, resulting in the reduction of resistance to failure. Similarly, the water penetrating the soil not only tends to reduce the suction and soften the soil, degrading its strength properties, but also applies an additional water pressure, increasing the driving forces [4]. Furthermore, such cracks have posed problems in much of the geotechnical works directly or indirectly, since they affect the soil's compressibility, rate of consolidation, strength, and the rate of water re-entry [5]. The tension cracks present substantially reduced critical height to an unsupported vertical slope [6]. The walls with cohesive backfill tend to undergo large outward displacement during the life of the wall, as the tension cracks gets filled with relatively 
incompressible material and during the wetter season the soil swells, pushing out the wall. Similarly, longitudinal cracks along the pavement shoulder in central Thailand have been reported due to desiccation of the clay subgrade [7].

In addition to their effects in geotechnical works, shrinkage cracks have important implications on environmental science and agricultural disciplines too. Shrinkage cracks, within a short period of time, can cause the clay barrier system to malfunction through the formation of preferential flow paths in the barrier layers [8]. The presence of cracks on topsoil has different effects on the runoff and total erosion [9], and also the movement of fertilizers and pesticides to the root zone is impacted by the presence of these cracks [10]. Shrinkage cracks thus have led to a wide range of problems in diverse fields, and research to analyze their effects are vital. Estimation of the maximum depth of cracks in soil forms a crucial part in the analysis of the stability of slopes as well as in designing mitigative measures such as moisture barriers [4,11].

Analytical solutions for the estimation of the crack depth have been investigated by various authors. Morris et al. [5] used linear elasticity theory, Linear Elastic Fracture Mechanics (LEFM), and strength relationships to explain the propagating cracks. The solution they proposed was for the case of a steady-state suction distribution from the ground surface to water table with maximum suction at the surface and zero at the water table. Another analytical solution for estimation of crack depth was explained by Fredlund and Rahardjo [12] based on the Poisson's ratio, matric suction, a function of the groundwater table, and soil elastic moduli. Miller et al. [13] performed a laboratory test on a compacted clay simulating landfill liner and concluded that desiccation cracks could occur even for a low plasticity soil compacted at optimum moisture content.

Many non-linear processes like changes in stiffness with suction, changes in tensile strength with moisture content, and adhesion at interfaces involved in desiccation cracks often lead to difficulty for analytical solutions in representing its real behavior. To consider the changes in material properties during desiccation as well as complicated boundary conditions, numerical modelling has evolved. Amarasiri et al. [14] conducted a laboratory test in a long rectangular mold and used the material properties for numerical modelling of desiccation cracks using a distinct element code. The modelling could capture the essence of desiccation in terms of residual soil height, the number of cracks formed, crack initiation moisture content, and the widths of cracks. Vo et al. [15] used finite element code, including cohesive joints, for investigating crack initiation and propagation along with the formation of the crack family. Numerical modelling, though tending to simulate physical processes more accurately, comes in the cost of time and complexity. They may not be appropriate in all scenarios and thus should always be validated with the field behavior.

This research presents a case study of the shrinkage crack observed on the surface of the clay dyke in Pathumthani, Thailand. The dyke is instrumented with various suction measuring devices and the crack depth along its crest has been periodically monitored, the data of which was used in the modelling of crack depth using the modified equation based on Fredlund and Rahardjo [12]. Such a procedure can provide a quick prediction of crack depth relative to suction for similar sites. Importantly, spectral analysis of surface waves (SASW) tests, the use of which has been quite rare in the investigation of shrinkage cracks, were used in determining the change in stiffness of soil with suction and the crack propagation. Periodical SASW tests together with the measurement of suction is proposed as a method for ascertaining the unseen cracks below the soil surface.

\section{Materials and Methods}

\subsection{Study Area and Instrumentation}

The studied site is a $10 \mathrm{~m}$-long section of a dyke in Pathumthani, Thailand [16] as shown in Figure 1. It was instrumented with various suction and moisture measuring devices, namely Kasetsart University (KU) tensiometers [17], flushable tensiometers, dielectric water potential sensors (matric potential sensor, MPS6), time domain reflectometry (TDR) sensors, as well as a rain gauge. The MPS6 
sensors, with the capacity of measuring suction from 9 to $10^{6} \mathrm{kPa}$, were installed at a depth of $0.5 \mathrm{~m}$ at the top, middle, and base of the embankment. TDR sensors were installed at a depth of $0.1 \mathrm{~m}$ in the same locations as the MPS6 sensors, so that the surface boundary condition could also be investigated. The measurements from the low-capacity tensiometers (A1, A2, A3) and flushable tensiometers (UNSUC1, UNSUC2) during the dry season were not considered in further shrinkage analysis due to cavitation problems, as higher suctions than the working range of the tensiometers were observed in the field in this period.

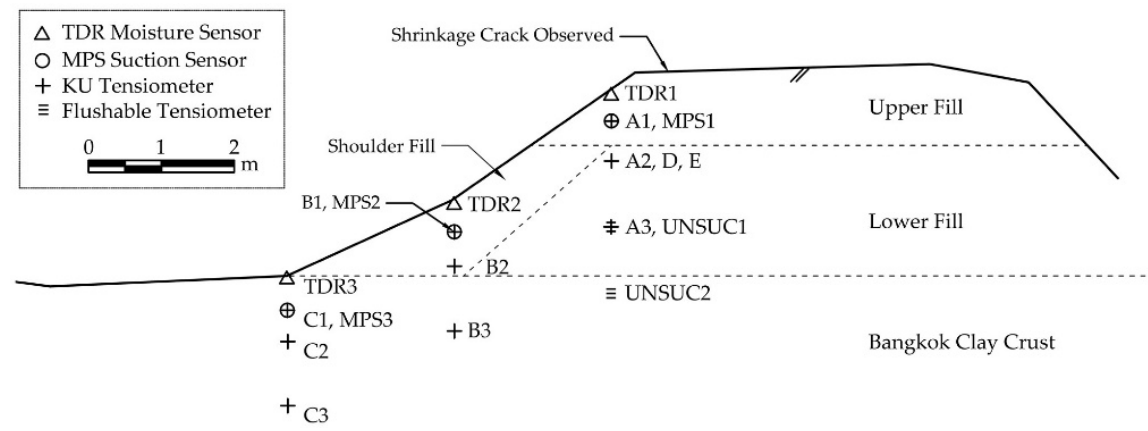

Figure 1. Schematic picture of the study site with various monitoring instruments.

Disturbed samples of soil were collected using a hand auger and test pits for basic tests of soil properties. The results from sieve analysis and Atterberg's limit tests are summarized in Table 1, from which, according to the unified soil classification system (USCS), the studied soil is classified as low-plasticity clay (CL).

Table 1. Basic physical properties of soil along with the unified soil classification system (USCS) classification. $\mathrm{CL}=$ low-plasticity clay.

\begin{tabular}{|c|c|c|c|c|c|c|c|c|}
\hline \multirow{2}{*}{$\begin{array}{l}\text { Depth of Soil } \\
\text { Sample Taken } \\
\text { from on Top of } \\
\text { the Embankment }\end{array}$} & $\begin{array}{c}\text { Gravel } \\
(\%)\end{array}$ & Sand (\%) & Silt (\%) & Clay (\%) & \multirow{2}{*}{$\begin{array}{l}\text { Liquid } \\
\text { Limit } \\
\text { (LL) } \%\end{array}$} & \multirow{2}{*}{$\begin{array}{l}\text { Plasticity } \\
\text { Index } \\
\text { (PI) }\end{array}$} & \multirow{2}{*}{$\begin{array}{c}\text { Shrinkage } \\
\text { Limit (SL) } \\
\%\end{array}$} & \multirow[t]{2}{*}{ USCS } \\
\hline & $\begin{array}{c}(>4.75 \\
\mathrm{mm})\end{array}$ & $\begin{array}{c}(4.75-0.074 \\
\mathrm{mm})\end{array}$ & $\begin{array}{c}(0.074-0.002 \\
\mathrm{mm})\end{array}$ & $\begin{array}{c}(<0.002 \\
\mathrm{mm})\end{array}$ & & & & \\
\hline $0.0-0.5 \mathrm{~m}$ & 12.0 & 22.8 & 23.9 & 41.3 & 43.8 & 22.4 & 13.5 & CL \\
\hline
\end{tabular}

The soil predominantly consisted of fine particles $(<0.074 \mathrm{~mm})$, with major fractions comprised of clay-sized particles. Some portions of gravel-sized particles were also present, which were primarily found at the top surface of the embankment. The Atterberg's limits were used as indicators to predict the expansion potential of the soil [18], such that a soil with a higher plasticity index exhibited a higher potential for expansion. The material in this study with a plasticity index (PI) of 22.4 was categorized with medium-high expansion potential.

The activity of clay $\left(\mathrm{A}_{\mathrm{c}}\right)$, defined as the ratio of the plasticity index to clay fraction was also considered as an indicator for expansion potential of the soil. $A_{c}$ based on the soil properties in Table 1 was 0.54 , which indicates possible clay minerals of kaolinite or illite [19]. Despite the medium expansion potential based on the Atterberg's limits, it is not uncommon for shrinkage cracks to occur even for soil with a PI as low as 6.9 or clay with illite mineralogy [13]. According to [20-22], swelling potential is not necessarily equal to that of shrinkage, and it is the soil properties such as initial density, initial moisture content, and magnitude of suction change that are the main factors affecting the swelling and shrinkage behavior.

\subsection{Soil Water Retention Curve (SWRC)}

The soil water retention curve (SWRC) was determined in the laboratory on an undisturbed sample, collected using a thin-wall miniature sampler. The specimen $(63 \mathrm{~mm}$ in diameter and about 20 
mm high) was wetted gradually while the equilibrated suction was continuously measured, until the value of suction nearly reached zero $(<0.1 \mathrm{kPa})$. Then, it was soaked for 2 weeks so that the soil sample became as close as possible to a fully saturated state. The soil sample was then allowed to dry slowly, while measuring the consequent suction using a miniature tensiometer $[17,23]$ for a suction range of $0-100 \mathrm{kPa}$. The pressure plate technique was used to measure suction in the range of $100-1500 \mathrm{kPa}$ and for suction higher than $1500 \mathrm{kPa}$, the isopiestic technique [12] was used. For the pressure plate technique, the sample was equilibrated with matric suction in the order of 200,800 , and $1500 \mathrm{kPa}$. Similarly, for the isopiestic technique, the sample was equilibrated with total suction in the order of $14,029,23,645,39,370$ and $365,622 \mathrm{kPa}$. In this study, only shrinkage behavior was considered and thus only the drying portion of the SWRC is presented. The height and diameter of the samples were measured at each stage of drying in order to calculate the volumetric strain.

\subsection{Free-Free Resonant Frequency (FFR) Test}

The FFR testing was selected to measure the shear wave velocity and the low-strain shear modulus of the compacted samples because of the method's reliability and simplicity [24-26]. The measured fundamental frequency along with the length, $L$, and density, $\rho$, of the sample were used to calculate the shear wave velocity, $\mathrm{V}_{\mathrm{s}}$, and the shear modulus, $\mathrm{G}_{0}$, using Equations (1) and (2):

$$
\begin{aligned}
& \mathrm{V}_{\mathrm{s}}=2 \mathrm{f}_{\mathrm{n}} \mathrm{L} \\
& \mathrm{G}_{0}=\rho \mathrm{V}_{\mathrm{s}}{ }^{2}
\end{aligned}
$$

In this study, a cylindrical soil sample of $50 \mathrm{~mm}$ in diameter and $100 \mathrm{~mm}$ in height was compacted statically at $95 \%$ of the maximum dry density to replicate the target compaction level in the field. Only the soil particles smaller than $4.75 \mathrm{~mm}$ (sieve No. 4) were used when preparing the specimens to avoid inaccurate results owing to large particle inclusion in the FFR tests. The experimental setup for the FFR tests is shown in Figure 2a, in which the specimen was laid on foam, simulating the free boundary condition. The sample was excited by perpendicularly tapping one end, inducing torsional motion with a small, in-house developed hammer. The attached accelerometer at the other end of the sample recorded the waves in the time domain which was then Fourier transformed into the frequency domain using a spectrum analyzer. A typical result from the FFR tests is shown in Figure $2 b$. The tests were performed along the drying and wetting paths to obtain the stiffness of the samples at various moisture contents, demonstrating the effects of suction.

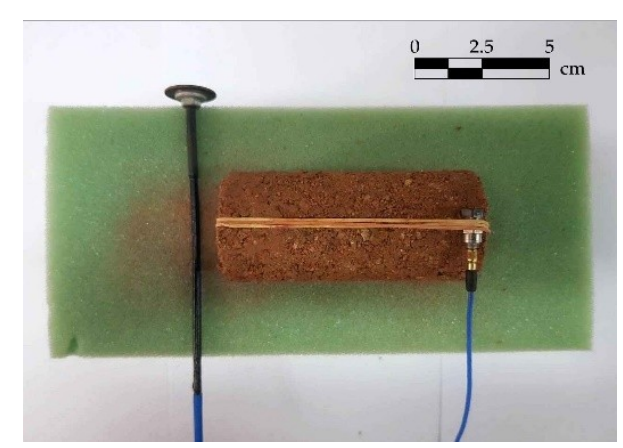

(a)

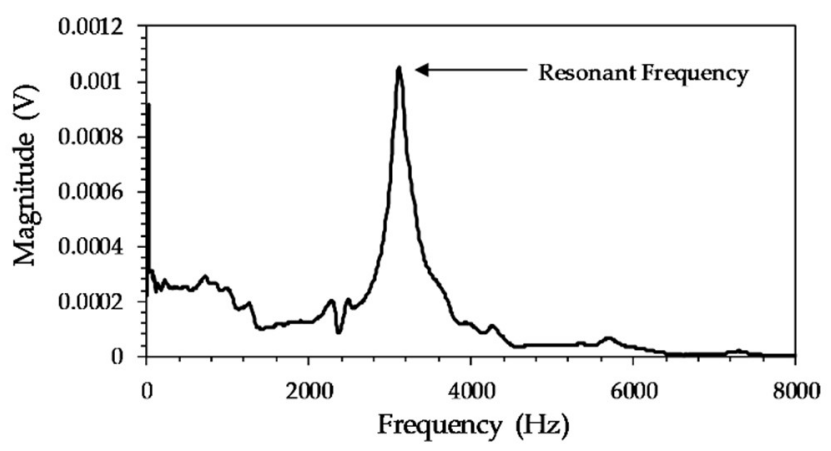

(b)

Figure 2. Experimental setup and an example of data acquisition through the free-free resonant frequency (FFR) test. (a) Sample with an accelerometer attached at one end. (b) Accelerometer data of the frequency domain with the fundamental frequency indicated by a peak. 


\subsection{Spectral Analysis of Surface Waves (SASW) Test}

Spectral analysis of surface waves (SASW), is an in-situ low-strain, non-destructive test developed by the University of Texas at Austin. This geophysical method has been successfully utilized to determine the stiffness and elastic properties of pavements [25-28] and many other geotechnical structures such as dams and embankments [29-32].

In this study, a series of SASW tests were conducted at different periods for about one year on top of the embankment, where the shrinkage crack appeared during the dry season. Horizontal receiver spacings of $0.5,1,2$, and $4 \mathrm{~m}$ were adopted, employing a common receiver midpoint (CRMP) array test configuration. A sledgehammer and a small hammer were used as impact sources for investigating deeper and shallower profiles, respectively, while two $2 \mathrm{~Hz}$ geophones were used as receivers. The phase information from the field was received via a spectrum analyzer and, later, the dispersion curves and shear wave velocity profiles were generated by using an iterative forward modelling technique [33]. The results elucidated the change in in-situ shear wave velocity of the embankment, before and after propagation of the crack.

\subsection{Measurement of Shrinkage Cracks}

A shrinkage crack was observed to first appear during December 2018. The expected crack initiation time was estimated based on the interval camera installed at the top of the slope [16] and periodic visual observations. The depth of the shrinkage crack in the field was measured using a flexible metallic strip (Figure 3) at various positions, and the average values were calculated. The measured values of crack depth along with the suction values are shown in Table 2 . It should be noted that the suction was measured at $0.5 \mathrm{~m}$ depth while the cracked zone above it could be of higher suction. It was, however, assumed in this study that the suction at $0.5 \mathrm{~m}$ depth was representative of the whole crack zone. The depth of the crack increased progressively with the suction value observed in the field, while in April 2019, the crack was closed due to rain infiltration, and subsequent soil swelling. There could have possibly been some crack filling with loose surface soil washed down upon wetting, though this was expected to be minor.

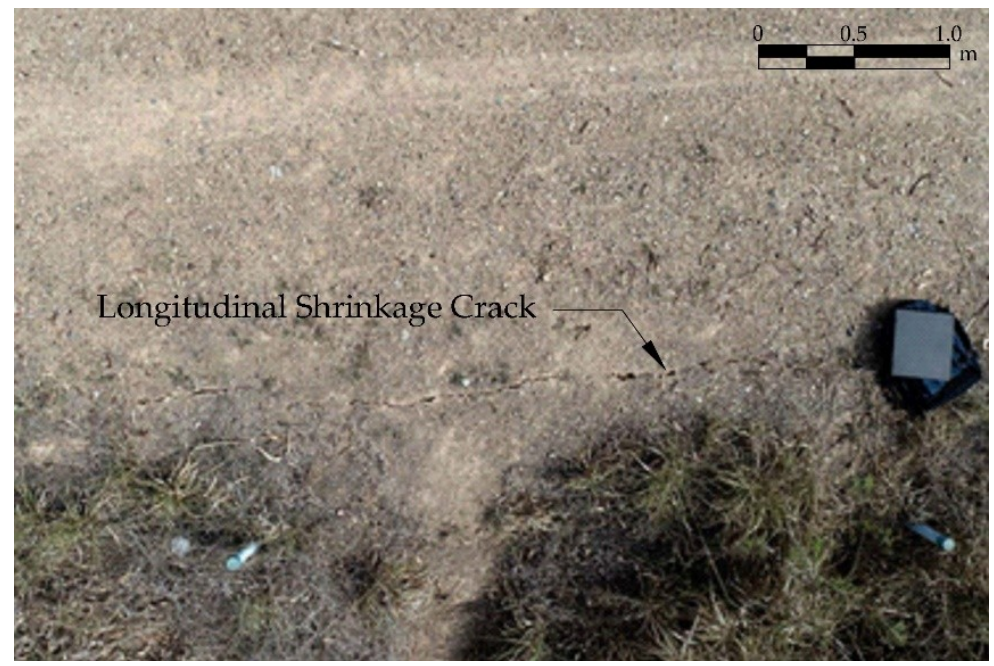

(a)

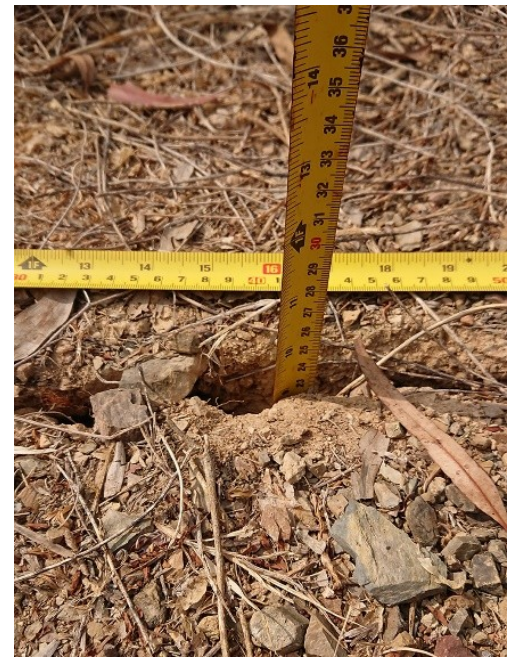

(b)

Figure 3. Shrinkage crack at the top of the embankment on 15 February 2019 (a) Top (drone) view of the crack (b) Measurement of the crack. 
Table 2. Measured crack depth (cm) in different months of 2019.

\begin{tabular}{ccc}
\hline Month & Crack Depth $\mathbf{( c m )}$ & Suction $(\mathbf{k P a})$ \\
\hline 09 January & 17.5 & 527.3 \\
15 February & 27.0 & 815.9 \\
29 March & 28.0 & 863.0 \\
28 April & - & 167.9 \\
\hline
\end{tabular}

\section{Results and Discussions}

\subsection{Instrumentation Results}

Figure 4 shows the suction and rainfall data for a period of about one year (15 May 2018-15 May 2019), along with indication of the periods in which crack depths were measured. It should be noted that only the suction data from MPS6-1 located at a depth of $0.5 \mathrm{~m}$ from top of embankment was used in the modelling of shrinkage crack depth as it was the nearest sensor in proximity to the crack.

From the middle of May to the end of October 2018, which was the rainy period, there was a significant amount of rainfall (about $750 \mathrm{~mm}$ ) compared to the period between November and April 2019 with rain of only about $100 \mathrm{~mm}$. The suction change agreed well with the rainfall pattern. In June 2018 , the value of suction at the $0.5 \mathrm{~m}$ depth was the lowest (about $9 \mathrm{kPa}$ ) while in the following months as rainfall became scant, the suction continuously increased and reached the highest value of $935 \mathrm{kPa}$ in the month of March 2019. The shrinkage crack started appearing in December 2018, when the value of suction rose to $318 \mathrm{kPa}$. The increase in suction (i.e., decrease in pore-water pressure) during the dry season was more considerable at the middle part of the slope (MPS6-2) than the top part (MPS6-1), while the suction at the base (MPS6-3) was the lowest. The higher pore-water pressure at the base of a slope was expected due to gravitational flow either as runoff or seepage and accumulation at the bottom. The underlying ground with a lower permeability could pose additional resistance to vertical flow, potentially resulting in ponding. The rise of pore-water pressure in response to rain infiltration appeared to be faster at the middle and lower parts than at the top. This is expected to be due to a lesser degree of compaction and the vegetation effect on the slope surface (i.e., at the middle and the base) which resulted in a more permeable ground than the well-compacted soil at the top surface of the dyke.

Figure 5 shows the response of volumetric water content from the TDR measurement. The response of the water content at a $0.1 \mathrm{~m}$ depth was expectedly faster than the suction at a $0.5 \mathrm{~m}$ depth. It can be seen that the sudden rise in volumetric water content took place whenever rainfall occurred, despite the relatively small amount of rain. Interestingly, by comparing TDR1 and MPS6-1 readings in Figures 4 and 5, the decrease in water content during the drying period (October to April 2019) seemed to be much less than that of the pore-water pressure. 


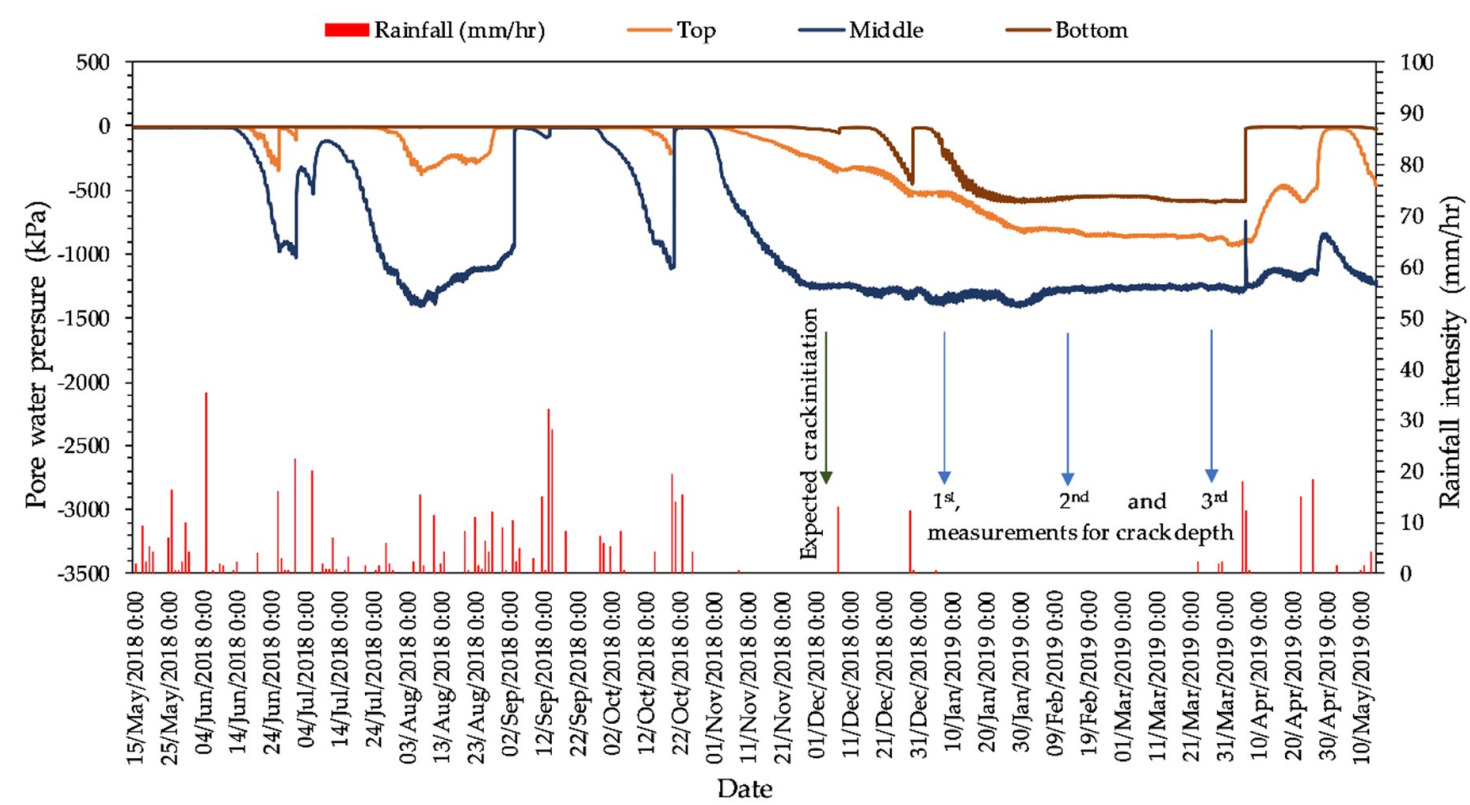

(a)

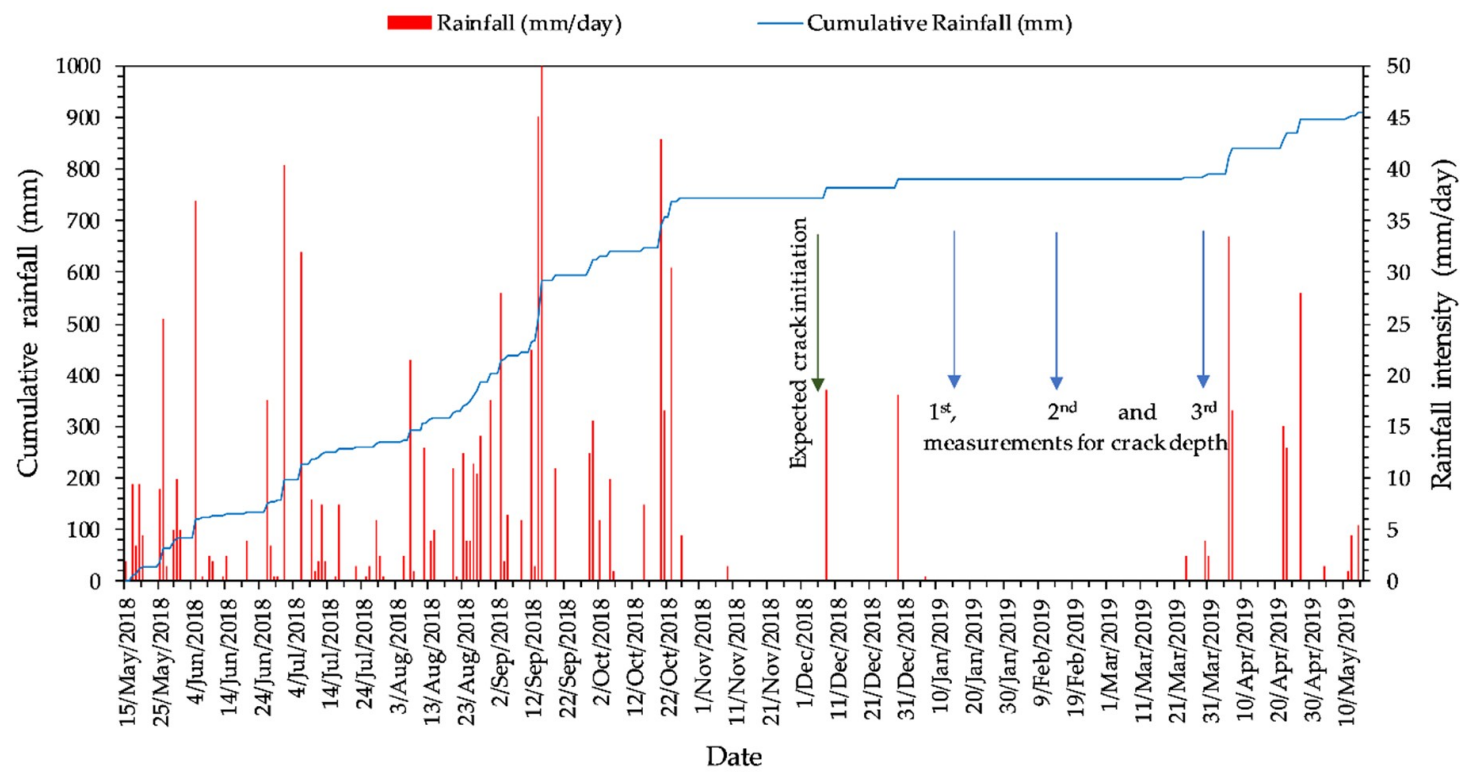

(b)

Figure 4. Results from MPS sensors and rain gauge for a period of one year. (a) Pore water pressure $(\mathrm{kPa})$ and rainfall intensity $(\mathrm{mm} / \mathrm{hr})$. (b) Rainfall intensity $(\mathrm{mm} / \mathrm{hr})$ and cumulative rainfall $(\mathrm{mm})$. 


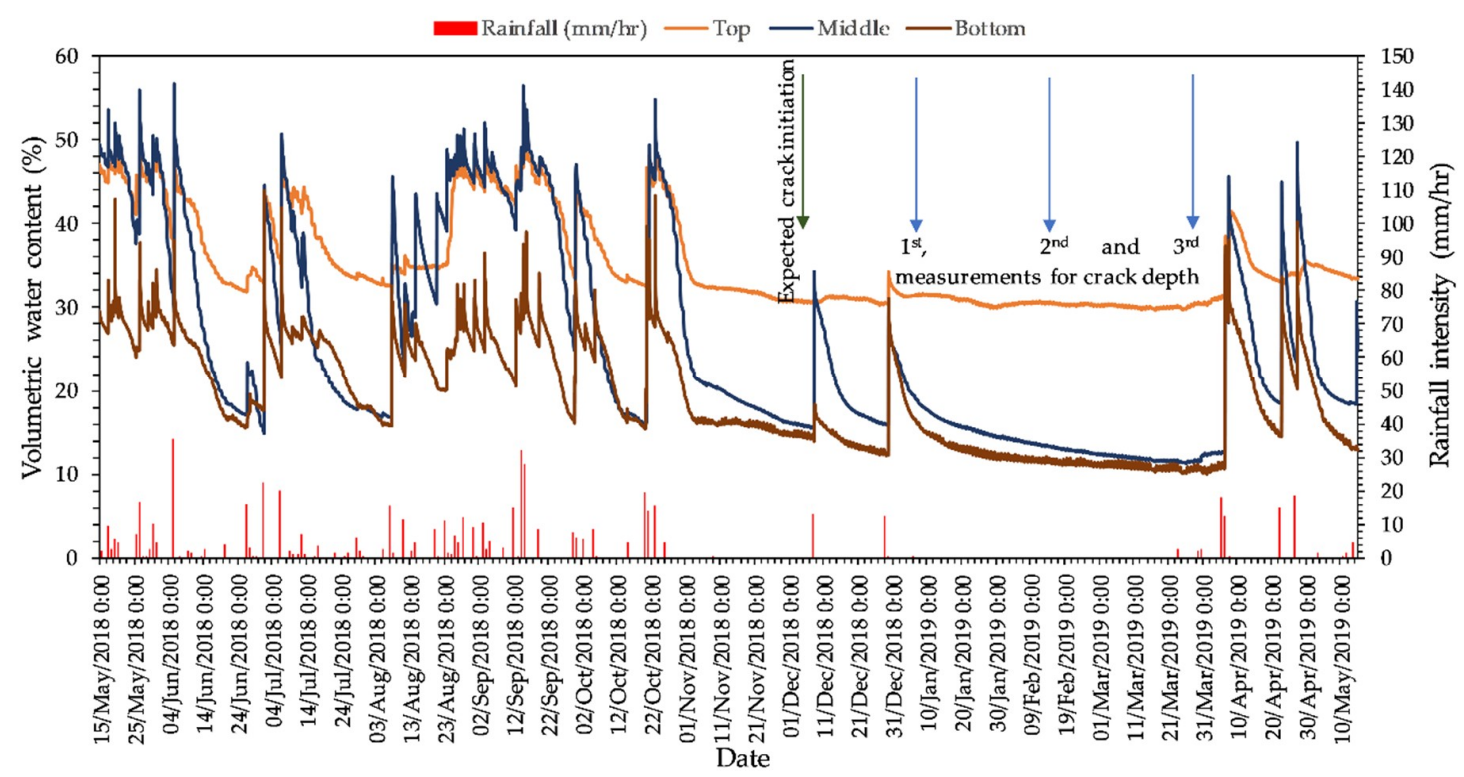

Figure 5. Results from the TDR measurements along with rainfall data for a period of one year.

\subsection{Soil Water Retention Curve (SWRC)}

Figure 6 shows the soil water retention curve (SWRC) of the undisturbed soil sample over the entire range of suction ( 0 to $1,000,000 \mathrm{kPa}$ ). The SWRC demonstrates the bimodality nature as indicated in Figure 6a, which can be attributed to the macro- and micro-voids associated with the undisturbed sample obtained from the field. Shrinkage of the soil upon drying (Figure 6b) can be clearly seen as a decrease in void ratio, which showed a linear trend against logarithmic soil suction for up to $10,000 \mathrm{kPa}$ while it demonstrated a constant void ratio after 10,000 $\mathrm{kPa}$.

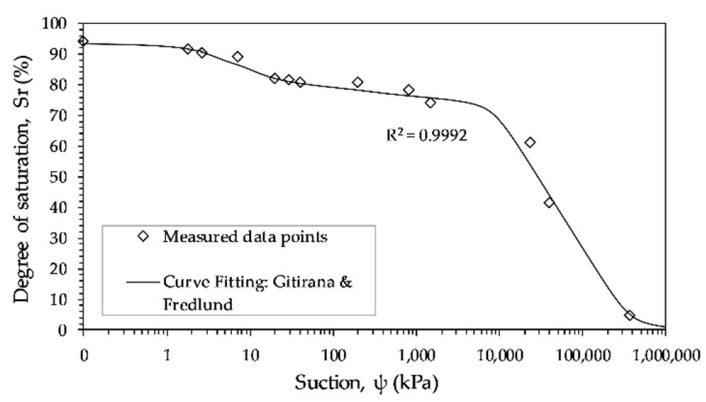

(a)

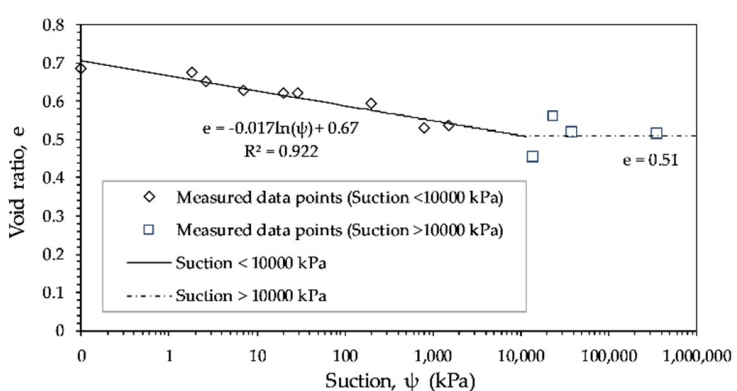

(b)

Figure 6. Soil water retention curve (SWRC) results. (a) A plot of degree of saturation against soil suction. (b) A plot showing the change in void ratio with respect to suction.

For modelling of the SWRC, the measured data points were fitted with the equations proposed by [34]. The model is comprised of the parameters that have clear physical meanings and the degree of saturation in the model is a function of ten parameters, as demonstrated in Equation (3),

$$
\mathrm{S}=\mathrm{f}\left(\psi_{\mathrm{b} 1}, \psi_{\text {res1 }}, \mathrm{S}_{\text {res1 }}, \psi_{\mathrm{b} 2}, \mathrm{~S}_{\mathrm{b} 2}, \psi_{\text {res2 }}, \mathrm{S}_{\text {res } 2}, \mathrm{a}, \mathrm{S}_{\max }, \psi\right)
$$

The value of the parameters used to fit the measured data points in this study are given in Table 3 , where $\psi_{\mathrm{b} 1}$ is the air-entry suction, $\psi_{\text {res }}$ is the residual suction, and $\mathrm{S}_{\text {res }}$ is the degree of saturation at the residual stage. The Subscripts 1 and 2 represent two levels of soil structures. $S_{b 2}$ is the degree of saturation at the air entry of the second structure level. Furthermore, a plot of gravimetric water content (w) with suction is shown in Figure 7. 


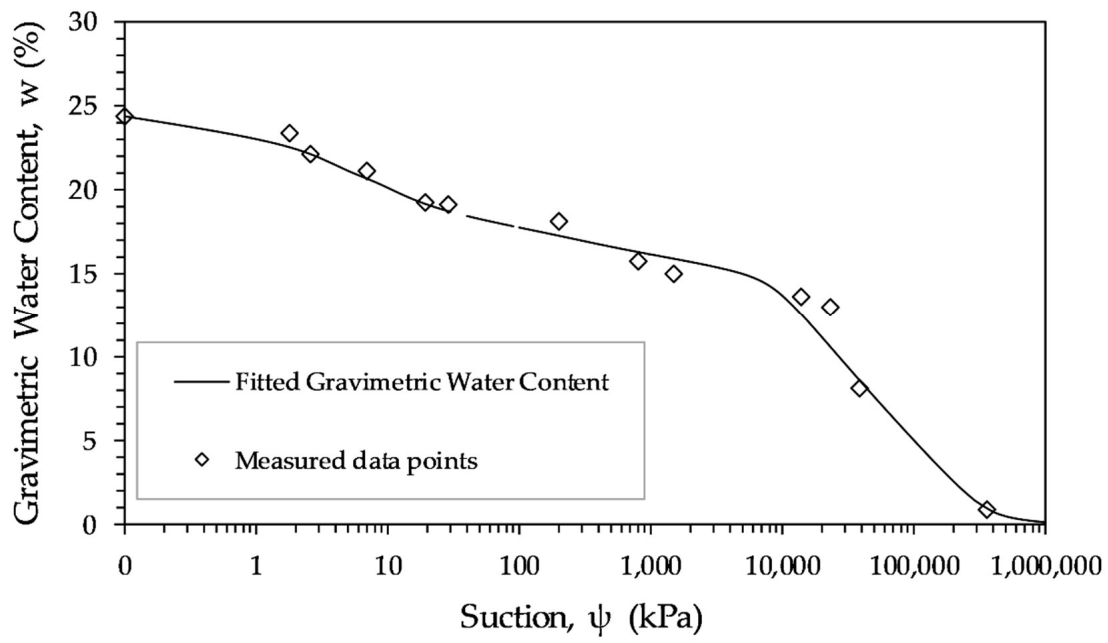

Figure 7. A plot of gravimetric water content and soil suction.

This relationship was also used for correlating the FFR results with suction. The fitted gravimetric water content for the soil with specific gravity (Gs) 2.65 was obtained from Equation (4), in which the void ratio (e) is a function of suction.

$$
\mathrm{w}=\frac{\text { Sr. e }}{\mathrm{Gs}}
$$

Table 3. Value of fitting parameters used in the model.

\begin{tabular}{ccccccccc}
\hline \multicolumn{10}{c}{ Fitting Parameters } \\
\hline $\mathrm{a}$ & $\psi_{\mathrm{b} 1}$ & $\psi_{\text {res1 }}$ & $\mathrm{S}_{\text {res1 }}$ & $\psi_{\mathrm{b} 2}$ & $\mathrm{~S}_{\mathrm{b} 2}$ & $\psi_{\text {res2 }}$ & $\mathrm{S}_{\text {res2 }}$ & $\mathrm{S}_{\max }$ \\
0.05 & 3.5 & 12 & 0.85 & 8500 & 0.8 & 365621 & 0.007 & 0.94 \\
\hline
\end{tabular}

The suction modulus (H) defined in Equation (5) is the ratio of change in suction $\left(\Delta\left(\mathrm{u}_{\mathrm{a}}-\mathrm{u}_{\mathrm{w}}\right)\right)$ to change in volumetric strain $\left(\Delta \epsilon_{\mathrm{vol}}\right)$ and is calculated using the drying SWRC results. It is plotted against suction as shown in Figure 8, which is seen to be increasing with an increase in suction, a typical trend observed in previous studies $[7,12]$. This function was then used in the modelling of crack depth, presented in Section 3.6

$$
\mathrm{H}=\frac{\Delta\left(\mathrm{u}_{\mathrm{a}}-\mathrm{u}_{\mathrm{w}}\right)}{\Delta \epsilon_{\mathrm{vol}}}
$$

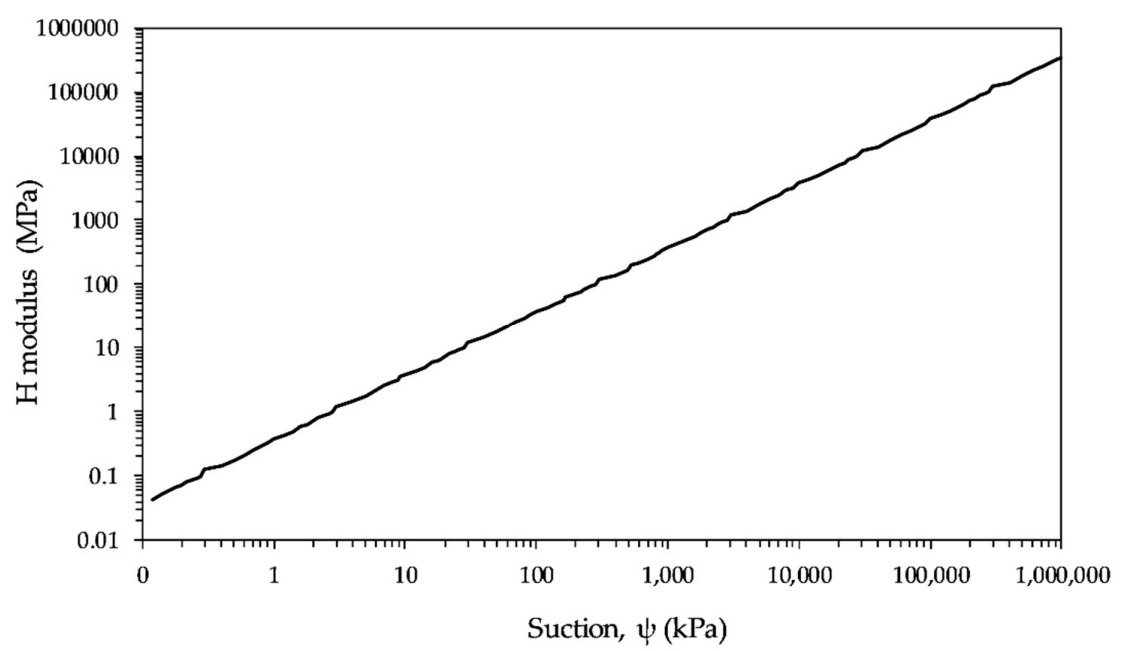

Figure 8. Variation of suction modulus $(\mathrm{H})$ with suction. 


\subsection{FFR Results}

The fundamental transverse frequency from the FFR tests was observed to be between 475 and $3350 \mathrm{~Hz}$ for various moisture contents. The shear wave velocity and the small strain shear modulus were calculated using Equations (1) and (2), respectively, the range of which were between 99.75 and $703.50 \mathrm{~m} / \mathrm{s}$ and 20.96-896.19 MPa. The small strain shear modulus increased with decreasing moisture content and increasing suction, as shown in Figure 9. This positive correlation between small-strain shear modulus with suction agrees well with findings of many previous studies $[24,35,36]$. The overall trend of $\mathrm{G}_{0}$ with moisture content and suction is bi-linear, with the turning point at a moisture content of about $10 \%$ and suction about $26 \mathrm{MPa}$.

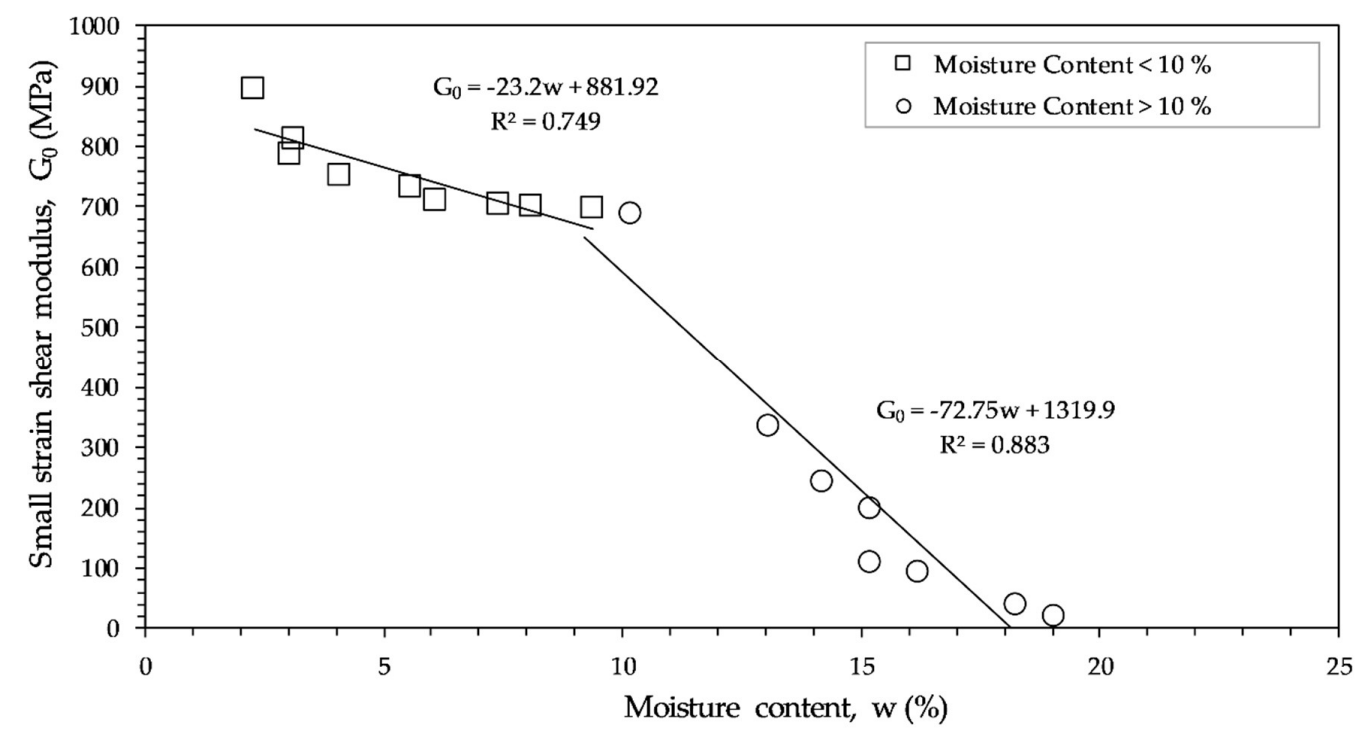

(a)

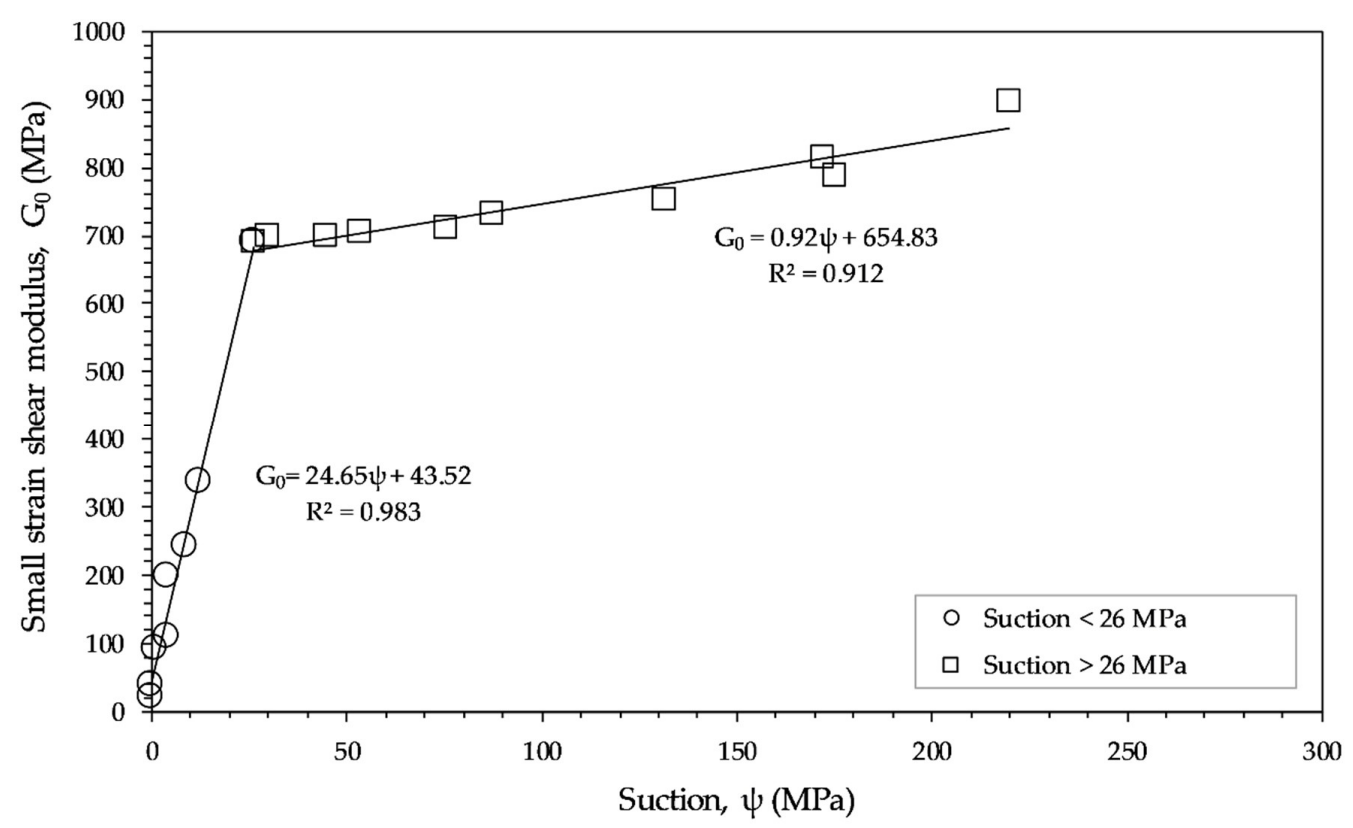

(b)

Figure 9. Bilinear variation of the small-strain shear modulus $\left(\mathrm{G}_{0}\right)$ from the FFR tests with (a) moisture content (b) suction. 
The trend of a sharp increase in $\mathrm{G}_{0}$ with decreasing moisture content (or increasing suction) at the initial stage of drying (suction from zero to $26 \mathrm{MPa}$ ) was expected and due to the greater influence of suction stress on the modulus [37] in this stage, as well as the initial decrease in the void ratio on the initial drying that could further induce a rise in modulus (Figures $6 \mathrm{~b}$ and $9 \mathrm{~b}$ ). This process continued until the turning point (at a suction of around $26 \mathrm{MPa}$ ) was reached where shrinkage became minimal, after which the rate of change in $\mathrm{G}_{0}$ became less. It is noteworthy that the moisture content at $26 \mathrm{MPa}$ suction was $10.2 \%$, which was lower than the soil's shrinkage limit of $13.5 \%$ and smaller than the second air-entry point of the SWRC (Figures 6 and 7). As drying continued, the sample showed a more gradual rate of increase in $\mathrm{G}_{0}$ for suction higher than $26 \mathrm{MPa}$ as shrinkage became progressively less with increasing suction.

\subsection{SASW Results}

SASW tests were set up longitudinally at the top of the embankment and were conducted at different time intervals to determine the change in modulus $\left(G_{0}\right)$ with varying in-situ suctions. Shear wave velocity (Vs) profiles for the embankment at different periods are shown in Figure 10. Only the Vs values obtained from zero to $0.5 \mathrm{~m}$ depth were used to calculate the $G_{0}$ of the upper layer of soil where the shrinkage crack was observed.

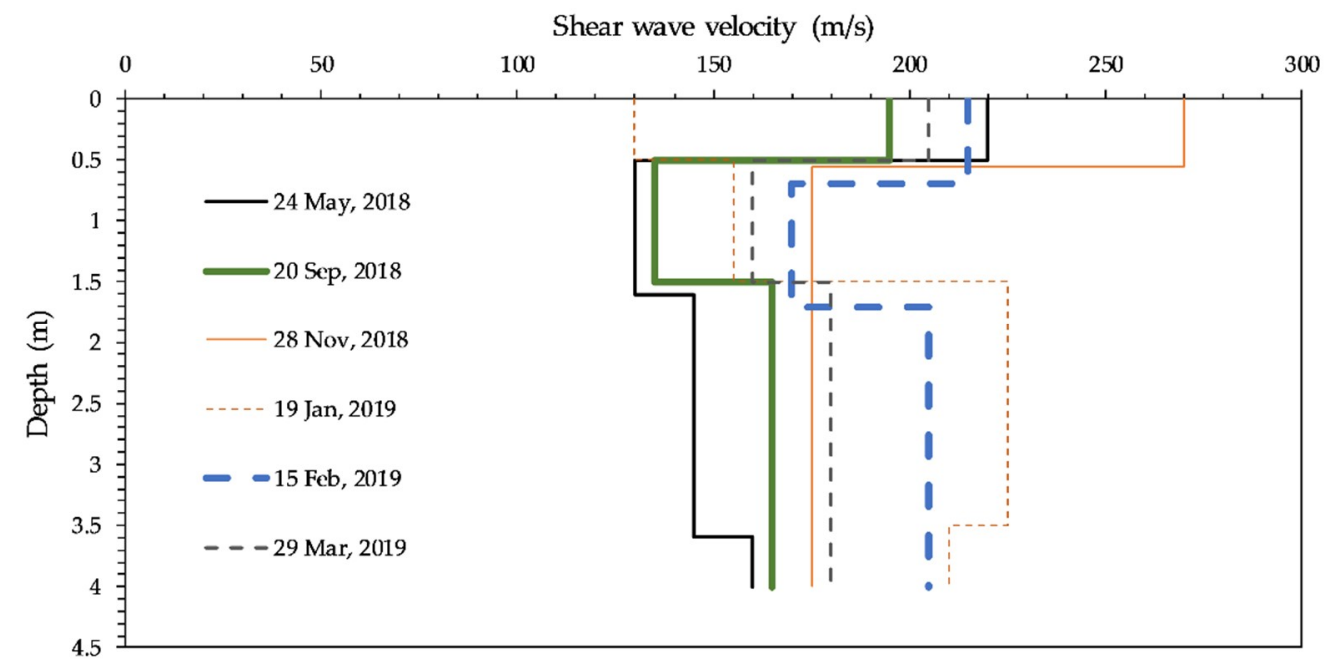

Figure 10. Shear wave velocity profiles of the clay embankment at different time periods.

The measured suction at the depth of $0.5 \mathrm{~m}$ (MPS6-1) was plotted against $\mathrm{G}_{0}$ as shown in Figure 11 . The $\mathrm{G}_{0}$ values from May to November 2018 positively correlate with measured suctions, while from January to March 2019, after the shrinkage crack occurred in December, the $G_{0}$ appeared to decrease significantly and varied disproportionately with suction. In general, $\mathrm{G}_{0}$ values from January to March should have been higher than those from May to November, since the suction values were higher for those periods, if they were to follow the trend of intact soil. A possible explanation is that the crack was responsible for the reduced values of $G_{0}$. 


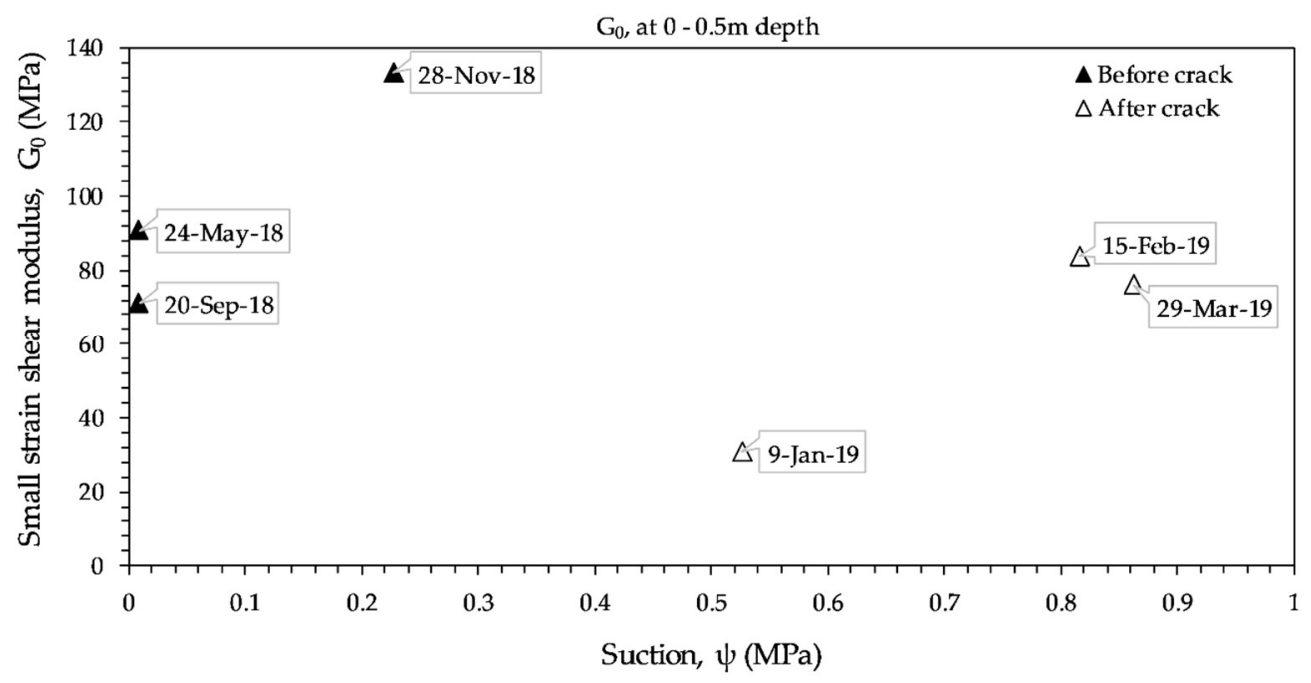

Figure 11. $G_{0}$ variations with suction, before and after crack.

\subsection{Suction-Small-Strain Shear Modulus Relationship}

Small-strain shear modulus $\left(\mathrm{G}_{0}\right)$ is dependent on net stress, suction history, void ratio, over-consolidation ratio (OCR), strain rate, and plasticity index [24,36,38-41]. Many empirical and semi-empirical expressions have been proposed for describing the relationship between suction and modulus. In this study, a modelling approach by [42] was used to determine the relationship between $G_{0}$, suction $(\psi)$, and water content due to its viability and directness. Amongst various modeling options, the model that considers the influence of suction stress and net stress separately is depicted in Equation (6),

$$
\mathrm{G}_{0}=\mathrm{A}^{*} \mathrm{f}(\mathrm{e})\left(\sigma_{\mathrm{o}}-\mathrm{u}_{\mathrm{a}}\right)^{\mathrm{n}}+\mathrm{CS}_{\mathrm{r}}{ }^{\mathrm{k}} \psi
$$

where $S_{r}$ is degree of saturation, $\sigma_{\mathrm{o}}$ is total vertical stress, $u_{\mathrm{a}}$ is pore air pressure, $\psi$ is soil suction (matric suction if $<1500 \mathrm{kPa}$, total suction if $>1500 \mathrm{kPa}$ ); $\mathrm{f}(\mathrm{e})=1 /\left(0.3+0.7 \mathrm{e}^{2}\right)$ and is the void ratio function given by [43] for sands and clays, A, C, and $\mathrm{k}$ are empirical parameters for obtaining the best fit between measured and predicted values.

In the FFR test, since the test was done in a free boundary condition state, the sample was devoid of any net confining pressure. However, in the SASW test, the interested depth involving the observed shrinkage crack was within $0.3 \mathrm{~m}$, so the net confining pressure involved can be considered marginal but not zero. Hence, the term, $A^{*} f(e)\left(\sigma_{o}-u_{a}\right)^{n}$ in Equation (6), which was assumed to be constant, $D$, would be higher in the SASW test than in the FFR test. Based on [37], suction stress, defined as suction multiplied by effective wetted area present at the interface, can be introduced as $\sigma_{\mathrm{s}}=\mathrm{S}_{\mathrm{r}}{ }^{\mathrm{k}} \psi,(\mathrm{k}=1 / 2)$, reducing Equation 6 to the form of,

$$
\mathrm{G}_{0}=\mathrm{D}+\mathrm{C} \sigma_{\mathrm{s}}
$$

The values of degree of saturation used in the calculation of $\sigma_{\mathrm{s}}$ were estimated using the SWRC and the measured suction. A reasonable goodness of fit ( $R^{2}$ ranging between 0.77 and 0.98$)$ was observed for the relationships $G_{0}-\psi$ (Figure 12a) and $G_{0}-\sigma_{s}$ (Figure 12b) for both the SASW and FFR results. In the FFR tests, the soil followed a bilinear relationship for both $G_{0}-\psi$ and $G_{0}-\sigma_{s}$ as explained earlier. Regarding the SASW, the $G_{0}-\psi$ relationship holds well $\left(R^{2}=0.905\right)$ until the initiation of the crack after which, despite the increase of suction, $\mathrm{G}_{0}$ decreased. It is interesting to note that after the crack, the values of $G_{0}$, in comparison to the expected $G_{0}-\psi$ and $G_{0}-\sigma_{\mathrm{s}}$ relationships, reduced and became similar to the FFR test. This may be because the effect of the crack was to reduce the net confining stress effect and thus to reduce the constant $D$ in Equation (7). The values of D and C obtained by curve fitting (Figure 12b) for different test conditions are listed in Table 4 . 


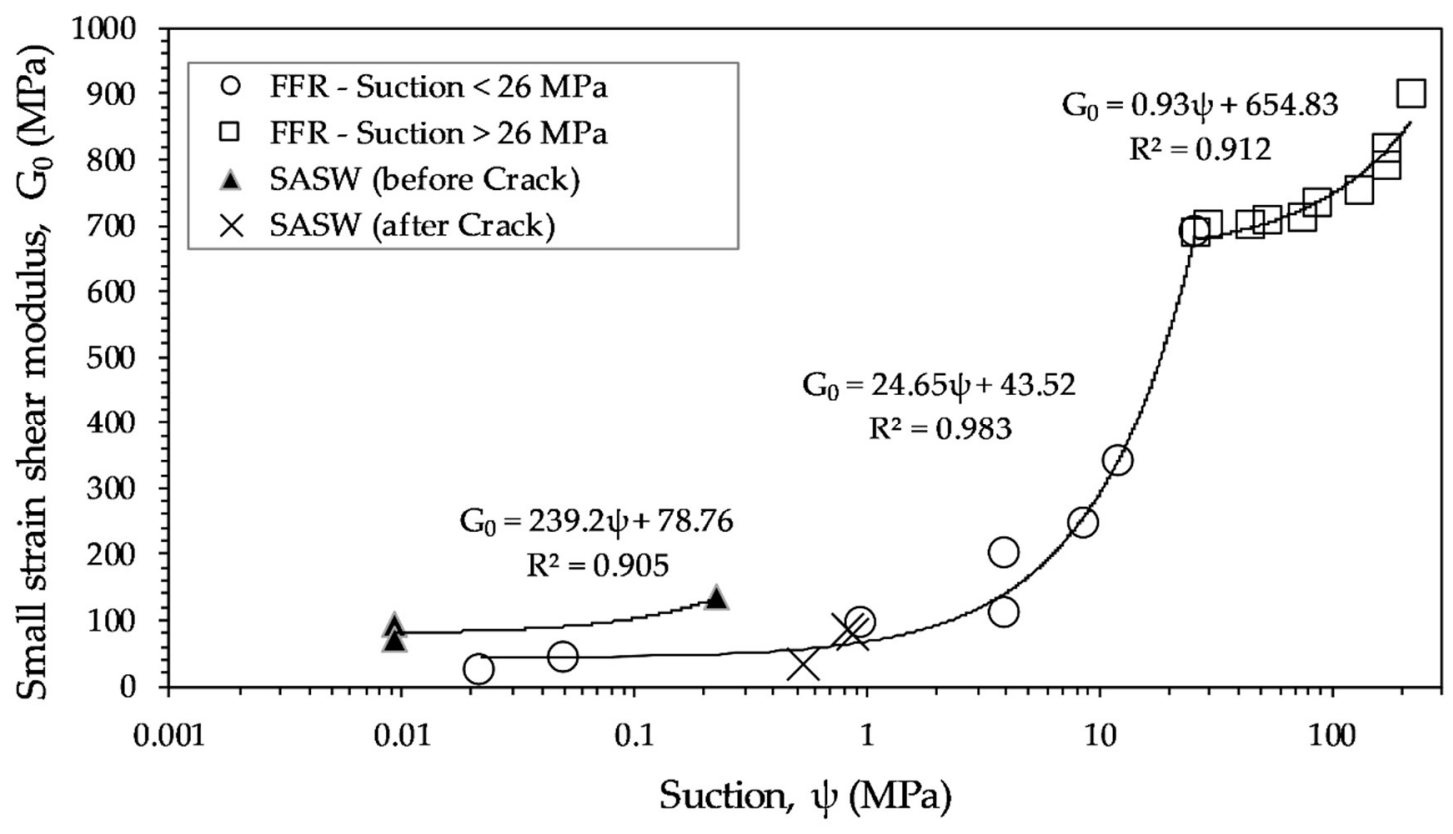

(a)

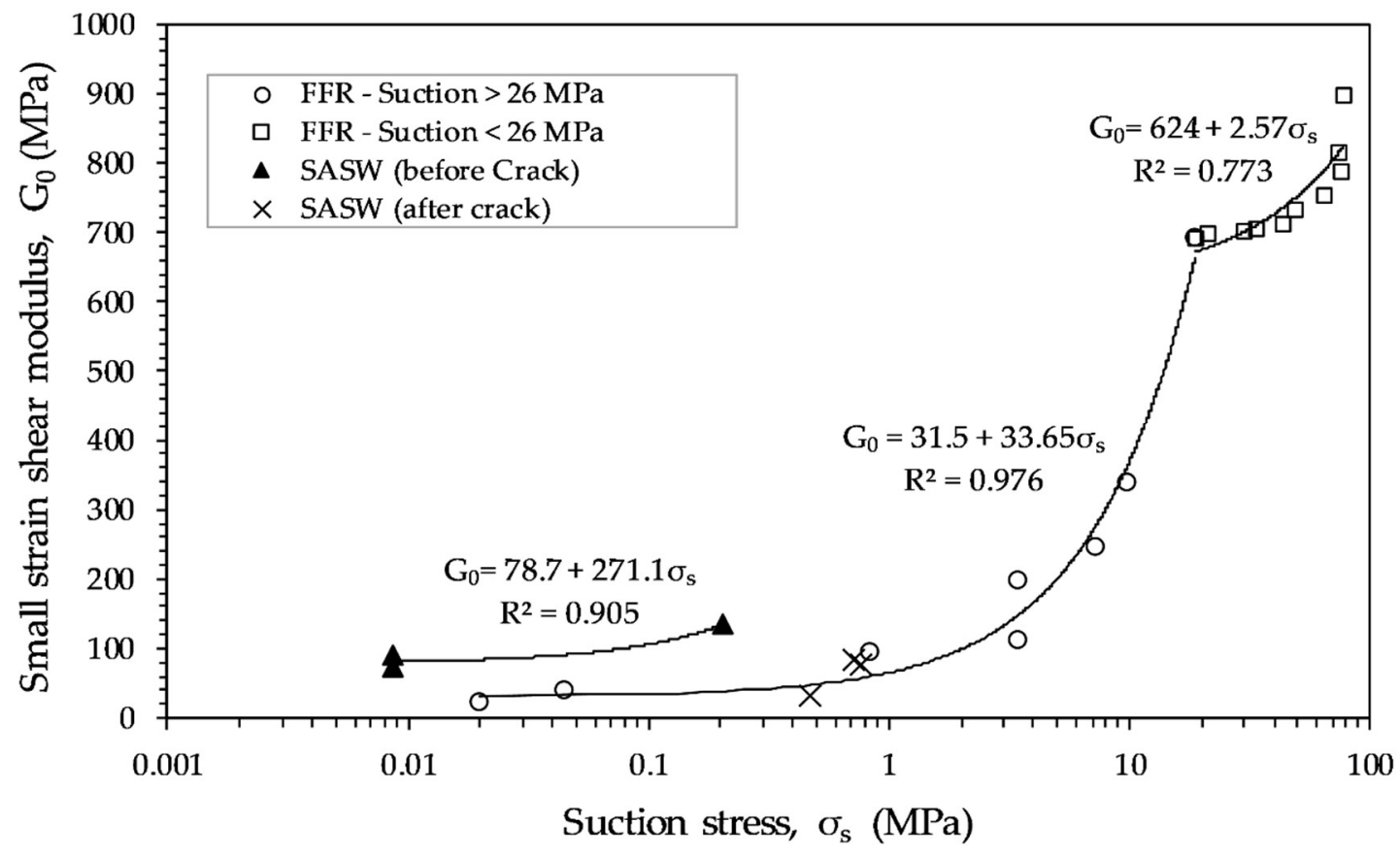

(b)

Figure 12. Modelling of the suction modulus relationship (a) $\mathrm{G}_{0}-\psi$ plot (b) $\mathrm{G}_{0}-\sigma_{\mathrm{s}}$ plot. $\mathrm{SASW}=$ spectral analysis of surface wave.

Table 4. Values of C and D parameters (from Equation (7)) obtained after curve fitting.

\begin{tabular}{cccc}
\hline $\mathrm{G}_{\mathbf{0}}-\boldsymbol{\sigma}_{\mathbf{s}}$ Relationship & $\mathbf{C}$ & $\mathbf{D} \mathbf{( M P a})$ & $\mathbf{R}^{2}$ \\
\hline SASW (before crack) & 271.1 & 78.7 & 0.905 \\
FFR $(\psi=0.02-26 \mathrm{MPa})$ & 33.65 & 31.5 & 0.976 \\
FFR $(\psi=26-220 \mathrm{MPa})$ & 2.57 & 624 & 0.773 \\
\hline
\end{tabular}




\subsection{Modelling of Crack Depth}

An attempt was made to model the measured crack depth by using a semi-empirical approach based on the isotropic elasticity principle (Equation (8)) given by [12]

$$
\Delta \varepsilon_{\mathrm{h}}=\frac{\Delta\left(\sigma_{\mathrm{h}}-\mathrm{u}_{\mathrm{a}}\right)}{\mathrm{E}}-\frac{\mu}{\mathrm{E}}\left(\Delta \sigma_{\mathrm{v}}+\Delta \sigma_{\mathrm{h}}-2 \Delta \mathrm{u}_{\mathrm{a}}\right)+\frac{\Delta\left(\mathrm{u}_{\mathrm{a}}-\mathrm{u}_{\mathrm{w}}\right)}{\mathrm{H}}
$$

where $\varepsilon_{\mathrm{h}}$ is a normal strain in the horizontal direction, $\mu$ is Poisson's ratio, $\sigma_{\mathrm{v}}$ and $\sigma_{\mathrm{h}}$ are the total normal stress in the vertical and horizontal directions, respectively, $\mathrm{u}_{\mathrm{a}}$ and $\mathrm{u}_{\mathrm{w}}$ are pore-air and pore-water pressures, respectively, $E$ and $H$ are elastic moduli with respect to changes in $\left(\sigma-u_{a}\right)$ and $\left(u_{a}-u_{w}\right)$, respectively. According to [5], the cracking mechanism mainly involves decreasing horizontal stress and, upon unloading, the soil tends to behave elastically. In addition, the soil closer to the surface behaves more isotropically than the deeper soil [5]. Thus, the isotropic elastic model was considered acceptable as a first approximation. For the at rest condition, $\Delta \varepsilon_{\mathrm{h}}$ can be set to zero. As $\Delta \sigma_{\mathrm{v}}, \Delta \mathrm{u}_{\mathrm{a}}$, and $\mathrm{u}_{\mathrm{a}}$ equal zero, and given the matric suction, $\psi=\mathrm{u}_{\mathrm{a}}-\mathrm{u}_{\mathrm{w}}$, Equation (8) reduces to the following,

$$
\Delta \sigma_{\mathrm{h}}=-\frac{\mathrm{E}}{\mathrm{H}(1-\mu)} \Delta \psi
$$

Provided that the initial ground condition is saturated and suction equals zero, the initial horizontal stress can be calculated using the expression $\mathrm{k}_{0} \gamma \mathrm{Z}_{\mathrm{c}}$, where $\mathrm{k}_{0}$ is the coefficient of earth pressure at rest, $\gamma$ is the unit weight of the soil, and $Z_{c}$ is the depth of the soil considered. $k_{0}$ is calculated using Jaky's formula, $\mathrm{k}_{0}=1-\sin \phi^{\prime}$, where $\phi^{\prime}$ is a friction angle obtained from the direct shear test. As suction increases, thereby causing a reduction in horizontal stress to the point when it becomes negative and equal to the tensile strength of the soil, $\sigma_{t}$, thus initiating a crack from the surface down to depth, $Z_{c}$. So, the required change in horizontal stress becomes $k_{0} \gamma Z_{c}+\sigma_{t}$. Then, Equation (9) can be arranged to give the value for depth of crack as [44],

$$
\mathrm{Z}_{\mathrm{c}}=\frac{\mathrm{E}}{\mathrm{k}_{0} \gamma \mathrm{H}(1-\mu)} \psi-\frac{\sigma_{\mathrm{t}}}{\mathrm{k}_{0} \gamma}
$$

Based on field observations, the crack started appearing when the suction value reached $318 \mathrm{kPa}$ in December 2018. Using this value and back-calculating the tensile strength from the material properties shown in Table 5 , the obtained value of $\sigma_{\mathrm{t}}$ was $32.7 \mathrm{kPa}$ at this suction level. The value of $\sigma_{\mathrm{t}}$ can be assumed as either a constant [44] (called Approach A in this study) or a function of suction according to [5] (called Approach B). For Approach A, differentiating Equation (10) gives,

$$
\mathrm{dZ}_{\mathrm{c}}=\frac{\mathrm{E}}{\mathrm{k}_{0} \gamma \mathrm{H}(1-\mu)} \mathrm{d} \psi
$$

Table 5. Summary of material properties used in modelling of crack depth.

\begin{tabular}{ccc}
\hline Properties & Values & Units \\
\hline Suction value at the onset of crack & 318 & $\mathrm{kPa}$ \\
H modulus at that suction & 9683 & $\mathrm{kPa}$ \\
$\mathrm{k}_{0}$ & 0.53 & - \\
Poisson's ratio, $\mu$ & 0.35 & - \\
Young's Modulus, E (large-strain) & 650 & $\mathrm{kPa}$ \\
Total unit weight, $\gamma$ & 18.3 & $\mathrm{kN} / \mathrm{m}^{3}$ \\
$\sigma \mathrm{t} /\left(\mathrm{k}_{0}^{*} \gamma\right)$ & 3.36 & $\mathrm{~m}$ \\
\hline
\end{tabular}


For Approach $B, \sigma_{t}$ is assumed as a function of unsaturated shear strength, which is dependent on suction as follows,

$$
\sigma_{\mathrm{t}}=\alpha_{\mathrm{t}} \cdot \psi \cdot \mathrm{S}_{\mathrm{r}} \cdot \tan \phi^{\prime}=\alpha_{\mathrm{t}} \cdot \mathrm{c}^{\mathrm{s}}
$$

where $c^{s}=\psi \cdot S_{r} \cdot \tan \phi^{\prime}$. The value of $\alpha_{t}$ corresponding to a suction level of $318 \mathrm{kPa}$ (at the initiation of the crack) is equal to 0.13357 based on back-calculation of $\sigma_{t}$ using Equation (12). As a first approximation, $\alpha_{t}$ is assumed to be independent of suction. Equation (10) can again be differentiated as

$$
\mathrm{dZ}_{\mathrm{c}}=\frac{\mathrm{E}}{\mathrm{k}_{0} \gamma \mathrm{H}(1-\mu)} \mathrm{d} \psi-\frac{1}{\mathrm{k}_{0} \gamma} \alpha_{\mathrm{t}} \cdot \mathrm{dc} \mathrm{c}^{\mathrm{s}}
$$

After December 2018, the tensile strength of the soil was exceeded by the suction-induced horizontal stress change and a crack started propagating. The modelling of the crack depth (Figure 1) was done by using an incremental form, as in Equations (11) and (13). The incremental cracking depth, $\mathrm{dZ}_{\mathrm{c}}$, was obtained with an incremental change in suction $\mathrm{d} \psi=\mathrm{d}\left(\mathrm{u}_{\mathrm{a}}-\mathrm{u}_{\mathrm{w}}\right)$. The variation of the $\mathrm{H}$ modulus with suction in Figure 8 was then used to find the E/H variation as shown in Figure 13, which was inputted in Equation (13) to calculate $\mathrm{dZ}_{\mathrm{c}}$ for each increment. The modelled crack depth, $\mathrm{Z}_{\mathrm{c}}$, non-linearly increased at a reduced rate as the suction value increased. The range of the $\mathrm{E} / \mathrm{H}$ ratio for this study was obtained by varying the E value until attaining the best fit, and was shown to vary between 0.005 and 0.002 for the suction value ranging from $318 \mathrm{kPa}$ to $1000 \mathrm{kPa}$. It should be noted that the E modulus in Table 3 corresponds to a large-strain condition as opposed to the small-strain modulus shown in Figure 12. Approach B (varying tensile strength) was also used to fit the variation of $Z_{c}$ as shown in Figure 13. Both approaches (A and B) appeared to yield similar results, which indicated that the $\sigma_{t}$ can be reasonably assumed as a constant, at least up to the investigated suction level.

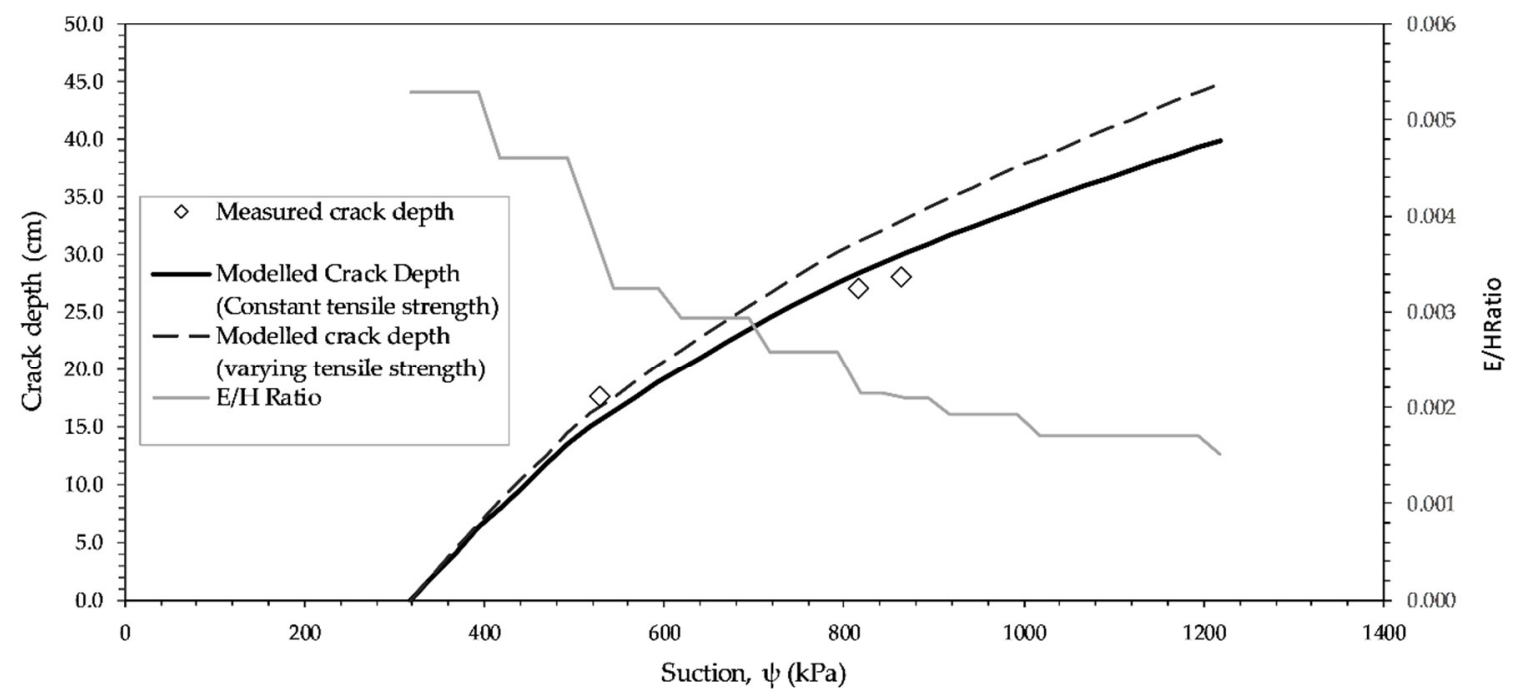

Figure 13. Modelling of crack depth relative to the suction.

\subsection{Potential Use of the Proposed Technique}

One of the major advantages of the proposed technique for determining the presence of cracks in-situ based on the SASW test is its non-destructiveness and ability to investigate larger areas. There were very few studies [45] that used geophysical tests in determining the depth of shrinkage cracks, though not explicitly considering the effect of suction. In this study, it has been clearly shown that the variations of $\mathrm{G}_{0}-\psi$ or $\mathrm{G}_{0}-\sigma_{\mathrm{s}}$ were dependent on test conditions and the presence of cracks. The $\mathrm{G}_{0}$ value of intact ground determined using the SASW test was normally greater than that of FFR at a given suction due to the influence of net confining pressure. However, as the increase in suction induced cracks in the ground, the horizontal stress was relieved, and the SASW tests yielded the $\mathrm{G}_{0}$ value similar to that of FFR as shown in Figure 14. Thus, with periodic measurement of suction and 
small-strain modulus using the SASW method, the presence of shrinkage cracks could be predicted underneath the soil layer where visual inspection may not be possible.

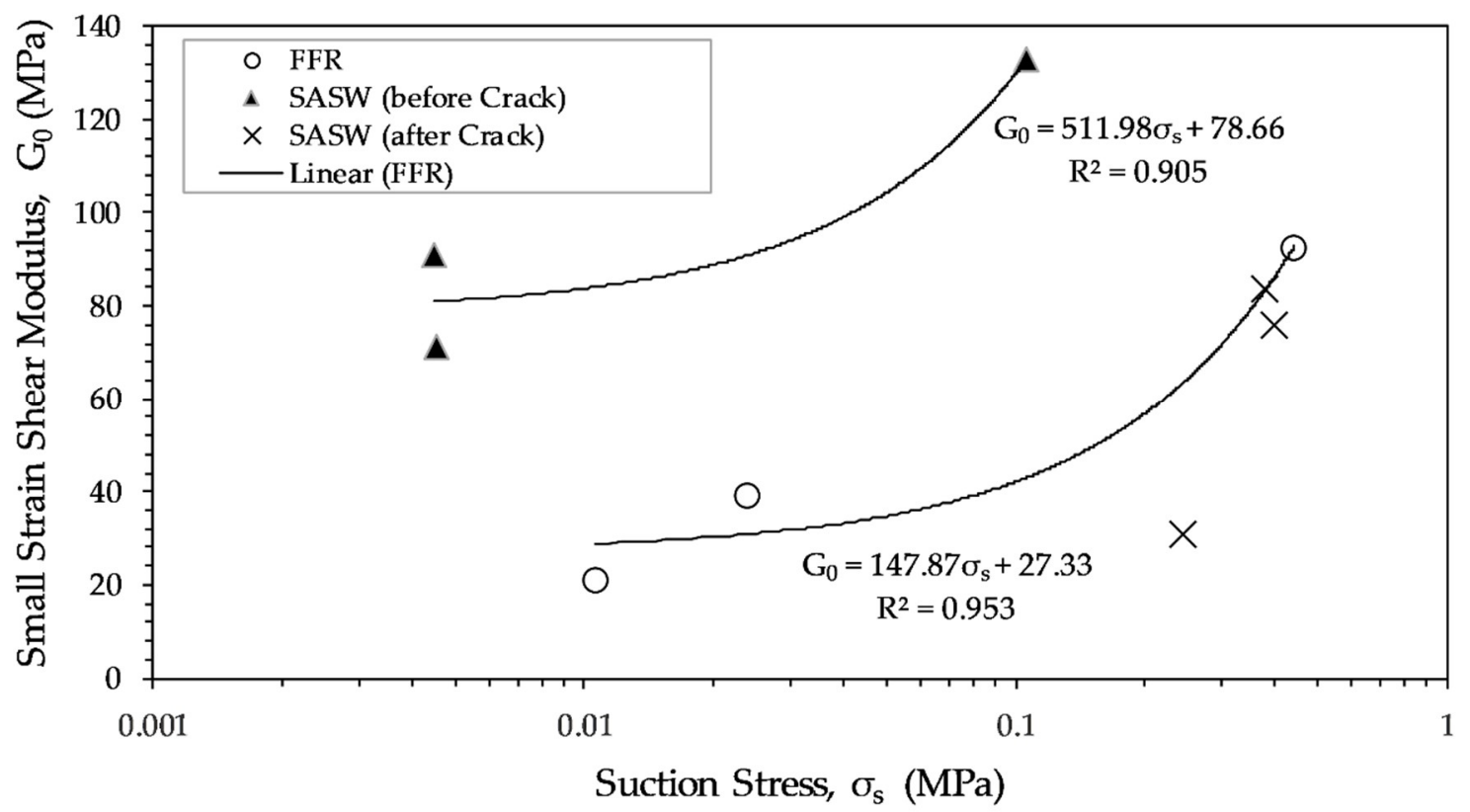

Figure 14. $\mathrm{G}_{0}-\sigma_{\mathrm{s}}$ relationship for a range of suction stresses occurring in the embankment.

\section{Conclusions}

The use of spectral analysis of surface waves (SASW) for periodic measurement of the modulus along with suction monitoring has been proposed to ascertain the shrinkage cracks that develop beneath the soil. The principle is based on the dependency of the small-strain modulus on suction and cracks. A drop in the small-strain modulus determined using the SASW test despite the increase in suction is an indication of crack development as the horizontal stress is reduced. The semi-empirical solution based on the elasticity principle can also provide a fairly good estimate of the crack depth as verified using field measurements of crack depth.

Author Contributions: Conceptualization, A.J. and S.N.; methodology, S.C., S.N., and A.J.; validation, A.J., S.N., S.C., and S.S.; formal analysis, S.P, A.S., and A.J.; investigation, S.P. and A.S; resources, A.J., S.N., S.C., and S.S.; data curation, S.P. and A.S.; writing-original draft preparation, A.S. and A.J.; writing-review and editing, A.J, S.C, S.S., and S.N.; visualization, A.S. and S.P.; supervision, A.J., S.N., S.C., and S.S.; project administration, A.J.; funding acquisition, A.J., S.N., and S.P.

Funding: The research grant was provided by the Faculty of Engineering, Kasetsart University, Thailand, the Indonesia Endowment Fund for Education (LPDP) scholarship, and JSPS KAKENHI Grant Number 16H04405, Japan.

Acknowledgments: The authors are grateful to scholarships provided by the Department of Civil Engineering, Faculty of Engineering, Kasetsart University (KU), Bangkhen and the Indonesia Endowment Fund for Education (LPDP) scholarship provided throughout the research period. They are indebted for the support and encouragement received from all the staff members of the Geotechnical Division of KU. Valuable support received from the Soil Physics Laboratory of the Department of Soil Science as well as the Geotechnical Innovation Laboratory of the Department of Civil Engineering is highly appreciated.

Conflicts of Interest: The authors declare no conflict of interest.

\section{References}

1. Kaniraj, S.R.; Abdullah, H. Effect of berms and tension crack on the stability of embankments on soft soils. Soils Found. 1993, 33, 99-107. [CrossRef]

2. Lee, F.H.; Lo, K.W.; Lee, S.L. Tension crack development in soils. J. Geotech. Eng. 1988, 114, 915-929. [CrossRef] 
3. Day, R.W.; Axten, G.W. Surficial stability of compacted clay slopes. J. Geotech. Eng. 1989, 115, 577-580. [CrossRef]

4. Baker, R. Tensile strength, tension cracks, and stability of slopes. Soils Found. 1981, 21, 1-17. [CrossRef]

5. Morris, P.H.; Graham, J.; Williams, D.J. Cracking in drying soils. Can. Geotech. J. 1992, 29, 263-277. [CrossRef]

6. Pufahl, D.; Fredlund, D.; Rahardjo, H. Lateral earth pressures in expansive clay soils. Can. Geotech. J. 1983, 20, 228-241. [CrossRef]

7. Jotisankasa, A.; Vadhanabhuti, B.; Lousuphap, K.; Sawangsuriya, A. Mechanisms of Longitudinal Cracks Along Pavement Shoulder in Central Thailand. In Unsaturated Soils: Theory and Practice; Kasetsart University: Bangkok, Thailand, 2011; pp. 699-705.

8. Albright, W.H.; Benson, C.H.; Gee, G.W.; Abichou, T.; Tyler, S.W.; Rock, S.A. Field performance of three compacted clay landfill covers. Vadose Zone J. 2006, 5, 1157-1171. [CrossRef]

9. Inoubli, N.; Raclot, D.; Moussa, R.; Habaieb, H.; Le Bissonnais, Y. Soil cracking effects on hydrological and erosive processes: A study case in Mediterranean cultivated vertisols. Hydrol. Proc. 2016, 30, 4154-4167. [CrossRef]

10. Prendergast, J.B. Soil water bypass and solute transport under irrigated pasture. Soil Sci. Soc. Am. J. 1995, 59, 1531-1539. [CrossRef]

11. Wijesooriya, R.M.S.D. Modelling of desiccation crack depths in clay soils. Ph.D. Thesis, Monash University, Melbourne, Australia, December 2012.

12. Fredlund, D.G.; Rahardjo, H. Soil Mechanics for Unsaturated Soils; John Wiley \& Sons: Austin, TX, USA, 1993.

13. Miller, C.J.; Mi, H.; Yesiller, N. Experimental analysis of desiccation crack propagation in clay liners 1. JAWRA J. Am. Water Resour. Assoc. 1998, 34, 677-686. [CrossRef]

14. Amarasiri, A.L.; Kodikara, J.K.; Costa, S. Numerical modelling of desiccation cracking. Int. J. Numer. Anal. Methods Geomech. 2011, 35, 82-96. [CrossRef]

15. Vo, T.D.; Pouya, A.; Hemmati, S.; Tang, A.M. Modelling desiccation crack geometry evolution in clayey soils by analytical and numerical approaches. Can. Geotech. J. 2018, 56, 720-729. [CrossRef]

16. Jotisankasa, A.; Pramusandi, S.; Nishimura, S.; Chaiprakaikeow, S. Field Response of an Instrumented Dyke subjected to Rainfall. Geotech. Eng. J. SEAGS AGSSEA 2019, 50.

17. Mairaing, W.; Jotisankasa, A.; Soralump, S. Some applications of unsaturated soil mechanics in Thailand: An appropriate technology approach. Geotech. Eng. 2012, 43, 1-11.

18. Peck, R.B.; Hanson, W.E.; Thornburn, T.H. Foundation Engineering; Wiley: New York, NY, USA, 1974; Volume 10.

19. Skempton, A. The colloidal activity of clays. Sel. Pap. Soil Mech. 1953, 106-118.

20. Nelson, J.D.; Chao, K.C.; Overton, D.D.; Nelson, E.J. Foundation Engineering for Expansive Soils; Wiley Online Library: Austin, TX, USA, 2015.

21. Chen, F.H. Foundations on Expansive Soils; Elsevier: Berkeley, CA, USA, 2012; Volume 12.

22. Sawangsuriya, A.; Jotisankasa, A.; Anuvechsirikiat, S. Classification of Shrinkage and Swelling Potential of a Subgrade Soil in Central Thailand. In Unsaturated Soils: Research and Applications; Springer: New York, NY, USA, 2012; pp. 325-331.

23. Jotisankasa, A.; Mairaing, W. Suction-monitored direct shear testing of residual soils from landslide-prone areas. J. Geotech. Geoenviron. Eng. 2009, 136, 533-537. [CrossRef]

24. Barus, R.M.N.; Jotisankasa, A.; Chaiprakaikeow, S.; Sawangsuriya, A. Laboratory and field evaluation of modulus-suction-moisture relationship for a silty sand subgrade. Transp. Geotech. 2019, 19, 126-134. [CrossRef]

25. Nazarian, S.; Stokoe, K.H. In Situ Determination of Elastic Moduli of Pavement Systems by Spectral-Analysisof-Surface-Waves Method: Practical Aspects; The Center: Austin, TX, USA, 1985.

26. Chaiprakaikeow, S.; Soponpong, C.; Sukolrat, J. Development of a Quality Control Index of Cement Stabilized Road Structures using Shear Wave Velocity. In Proceedings of the 2nd World Congress on Civil, Structural, and Environmental Engineering (CSEE'17), Barcelona, Spain, 2-4 April 2017; pp. ICGRE113-110-ICGRE113-111.

27. Ismail, M.; Samsudin, A.; Rafek, A.; Nayan, K. Road pavement stiffness determination using SASW method. J. Civ. Eng., Sci. Technol. 2012, 3, 9-16. [CrossRef]

28. Nazarian, S.; Stokoe, I.; Kenneth, H.; Briggs, R.C.; Rogers, R.C. Determination of Pavement Layer Thicknesses and Moduli by SASW Method; Transportation Research Board: Washington, DC, USA, 1988. 
29. Bay, J.A.; Chaiprakaikeow, S. Spectral Analysis of Surface Waves (SASW) testing of Sirikit and Rajjaprabha Dams. In Electricity Generating Authority of Thailand (EGAT) Report, Bangkok, Thailand; Electricity Generating Authority of Thailand: Nonthaburi, Thailand, 2009.

30. Chaiprakaikeow, S.; Bay, J.A.; Chaowalittrakul, N. Study of Dynamic Properties of Mae Chang Dam using Spectral Analysis of Surface Waves and Resonance Tests. In Proceedings of the 21th National Convention on Civil Engineering, Songkla, Thailand, 28-30 June 2016.

31. Chaiprakaikeow, S.; Bay, J.A.; Chaowalittrakul, N.; Brohmsubha, P. Evaluation of the Effect of Concrete Blocks on Seismic Response of Bhumibol Dam using In-Situ Dynamic Tests. In Proceedings of the 85th Annual Meeting of International Commission on Large Dams (ICOLD2017), Prague, Czech Republic, 3-7 July 2017.

32. Bay, J.A.; Chaiprakaikeow, S. Spectral Analysis of Surface Waves (SASW) testing of Srinakarind and Vajiralongkorn Dams. In Electricity Generating Authority of Thailand (EGAT) Report, Bangkok, Thailand; Electricity Generating Authority of Thailand: Nonthaburi, Thailand, 2006.

33. Joh, S.H.; Stokoe, K.H. Advances in Interpretation and Analysis Techniques for Spectral-Analysis-of-Surface-Waves (SASW) Measurements; Offshore Technology Research Center: College Station, TX, USA, 1997.

34. De FN Gitirana, G., Jr.; Fredlund, D.G. Soil-water characteristic curve equation with independent properties. J. Geotech. Geoenviron. Eng. 2004, 130, 209-212. [CrossRef]

35. Mendoza, C.; Colmenares, J.; Merchan, V. Stiffness of an unsaturated compacted clayey soil at very small strains. In Proceedings of the International Symposium on Advanced Experimental Unsaturated Soil Mechanics, Trento, Italy, 27-29 June 2005; pp. 199-204.

36. Kaewsong, R.; Zhou, C.; Ng, C. Modelling effects of recent suction history on small-strain stiffness of unsaturated soil. Can. Geotech. J. 2018, 56,1-11. [CrossRef]

37. Lu, N.; Likos, W.J. Suction stress characteristic curve for unsaturated soil. J. Geotech. Geoenviron. Eng. 2006, 132, 131-142. [CrossRef]

38. Hardin, B.O.; Richart, F., Jr. Elastic wave velocities in granular soils. J. Soil Mech. Found. Div. 1963, 89, 3407.

39. Sorensen, K.K.; Baudet, B.; Simpson, B. Influence of strain rate and acceleration on the behaviour of reconstituted clays at small strains. Géotechnique 2010, 60, 751. [CrossRef]

40. Santos, J.; Correia, A.G. Shear modulus of soils under cyclic loading at small and medium strain level. In Proceedings of the 12th World Conference on Earthquake Engineering, Auckland, New Zealand, 30 January-4 February 2000.

41. Khosravi, A.; Shahbazan, P.; Pak, A. Impact of hydraulic hysteresis on the small strain shear modulus of unsaturated sand. Soils Found. 2018, 58, 344-354. [CrossRef]

42. Sawangsuriya, A.; Edil, T.B.; Bosscher, P.J. Modulus-suction-moisture relationship for compacted soils in postcompaction state. J. Geotech. Geoenviron. Eng. 2009, 135, 1390-1403. [CrossRef]

43. Hardin, B.O. The nature of stress-strain behavior for soils. In Proceedings of the ASCE Geotechnical Engineering Division Specialty Conference, Pasadena, CA, USA, 19-21 June 1978.

44. Miller, G.; Hassanikhah, A.; Varsei, M. Desiccation crack depth and tensile strength in compacted soil. In Proceedings of the 6th Asia Pacific Conference on Unsaturated Soils, Guilin, China, 23-26 October 2015.

45. Picornell, M.; Lytton, R.L. Field measurement of shrinkage crack depth in expansive soils. Transp. Res. Rec. $1989,1219,121-130$.

(C) 2019 by the authors. Licensee MDPI, Basel, Switzerland. This article is an open access article distributed under the terms and conditions of the Creative Commons Attribution (CC BY) license (http://creativecommons.org/licenses/by/4.0/). 